\title{
Escala de Preferência Musical: construção e comprovação da sua estrutura fatorial1
}

\author{
Carlos Eduardo Pimentel - Universidade Federal da Paraíba \\ Valdiney V. Gouveia - Universidade Federal da Paraíba² \\ Viviany Silva Pessoa - Universidade Federal da Paraíba
}

\begin{abstract}
Resumo
O objetivo deste estudo foi construir e conhecer os parâmetros psicométricos de uma escala para medir a preferência musical de jovens. Participaram da pesquisa 480 estudantes do ensino médio, majoritariamente do sexo feminino (55,1\%) e solteiros (95,8\%), com idades variando de 13 a 28 anos $(M=16,2 ; D P=1,60)$. Estes responderam à Escala de Preferência Musical, além de perguntas demográficas. A amostra foi dividida aleatoriamente em duas de igual tamanho, procurando conhecer a estrutura fatorial da escala $\left(\mathrm{n}_{1}\right)$ e logo testá-la $\left(\mathrm{n}_{2}\right)$. Os resultados de uma análise de componentes principais com a primeira amostra revelaram uma estrutura multifatorial, composta por quatro componentes de estilos musicais: música de massa, música alternativa, música refinada e música convencional, com índices de precisão satisfatórios e explicando mais da metade da variância total. Uma análise fatorial confirmatória (ML) foi realizada com a segunda amostra, testando a estrutura previamente observada. Os resultados razoavelmente apóiam tal estrutura. Conclui-se que esta é uma medida adequada para fins de pesquisa, sendo útil quando o propósito for conhecer a preferência musical dos adolescentes. Por outro lado, apontam-se limitações e sugestões para melhorar os parâmetros dessa medida.
\end{abstract}

Palavras-chave: Música; Preferência; Adolescente; Escala.

\section{Music Preference Scale: development and psychometric parameters}

\begin{abstract}
This study aimed at elaborating and knowing the psychometric parameters of a measure of musical preference among adolescents. Participated in the study 480 high school students, most of them female (55.1\%) and single (95.9\%), with age ranging from 13 to 28 years $(\mathrm{M}=16.2$; $\mathrm{SD}=1.60)$. They answered the Musical Preference Scale and demographic questions. The sample was randomically divided into two of equal sizes, searching to know the factor structure of the scale $\left(n_{1}\right)$ and than test it $\left(n_{2}\right)$. Results of the Principal Components analysis with the first sample indicated a multifactor structure, composed of four components of music styles: mass music, alternative music, refined music, and conventional music, which satisfactory reliabilities indices and accounting more than half of the total variance. A confirmatory factor analysis (ML) was performed with the second sample, testing the previously observed structure. Results reazonable support such structure. It was concluded that this is an adequate measure for research purposes, and it is useful when the goal is to know the adolescents musical preference. On the other hand, they were pointed out the limitations of the current study, and presented suggestions to improve the parameters of this measure.

Keywords: Music; Preference; Adolescent; Scale.
\end{abstract}

\section{Introdução}

O gosto ou a preferência pela música pode ser considerado um construto importante para a compreensão de traços de personalidade (Mcnamara \& Ballard, 1999), comportamentos (Villani, 2001), atitudes e valores (North, Desborough \& Skarstein, 2005). A propósito, Schwartz e Fouts (2003) afirmam que as preferências musicais podem ser uma via de acesso à realidade interior dos adolescentes, servindo como "janelas" do universo destes, além de refletir sua personalidade, seus valores, os conflitos vivenciados e as questões relacionadas ao cotidiano. Apesar disso, esta é uma variável de pouca notoriedade na literatura da psicologia social e da personalidade (Rentfrow \& Gosling, 2003), demandando ainda muitos estudos nesta perspectiva.

Não obstante, o interesse em compreender a influência da música - de gêneros ou estilos musicais específicos no contexto social - é evidente já em grandes pensadores da Antigüidade, que são unânimes em sugerir sua relação com a personalidade, os

${ }^{1}$ Este artigo deriva da pesquisa de mestrado do primeiro autor, sob orientação do segundo, os quais agradecem o apoio recebido da CAPES, através de bolsa de Demanda Social, e do CNPq, por meio de Bolsa de Produtividade em Pesquisa.

2 Endereço para correspondência:

Universidade Federal da Paraíba - CCHLA - Departamento de Psicologia - 58035-120 - João Pessoa-PB

E-mail: vvgouveia@pesquisador.cnpq.brouvgouveia@cchla.ufpb.br 
sentimentos e os processos de influência social. Aristóteles (384-322 a. C.), por exemplo, refere-se à importância dos estilos musicais no caráter (Aristóteles, 1973), e Platão (427-347 a. C.), por sua vez, indica que a música poderia servir como um instrumento capaz de influenciar sociedades inteiras (Platão, 1993).

Atualmente, encontram-se referências à inserção de diversas disciplinas no estudo das ligações existentes entre a música, a sociedade e a cultura (Abdounur, 2002; Dayrell, 2002; Hobsbawm, 2004), como ocorre, por exemplo, na sociologia (ver Outhwaite \& Bottomore, 1996). Na psicologia social contemporânea, provavelmente o manual Social psychology of music, de Paul Randolph Farnsworth, publicado em 1969, tenha sido o primeiro a explorar o papel da música em temas básicos da disciplina (Farnsworth, 1969). Além dessa obra, existe o livro The social psychology of music, editado em 1997 por David J. Hargreaves e Adrian C. North (Hargreaves \& North, 1997), o qual se insere explicitamente na esfera psicossocial.

Parece evidente, pois, que mesmo sendo reconhecida como preponderante para entender e explicar o comportamento humano, a música tem recebido consideravelmente pouca atenção sistemática na psicologia. Esse aspecto é constatado já em relação à escassez de medidas que têm sido desenvolvidas para avaliar a preferência musical. A propósito, quando da época da seleção de medidas para esta pesquisa, as publicações revisadas que consideravam a preferência musical (Ballard, Dodson \& Bazzini, 1999; Binder, 1993; Hogan \& cols., 1996; McNamara \& Ballard, 1999; Schell \& Westefeld, 1999; Villani, 2001) não apresentavam uma escala validada para mensurar tal construto. Esta situação é extensiva ao cenário nacional vigente, em que recente revisão da literatura realizada no Index Psi (2006), considerando conjuntamente as palavras música, estilos musicais e/ou preferência musical, não permitiu identificar qualquer medida publicada acerca desse construto no Brasil. Tendo em conta esses aspectos, justifica-se o objetivo do presente estudo, que foi construir e conhecer os parâmetros psicométricos de uma medida de preferência musical no contexto brasileiro, permitindo futuramente conhecer seus antecedentes e conseqüentes. Antes de descrevê-la, procura-se resumir algumas pesquisas que têm relacionado a preferência musical com atitudes e comportamentos das pessoas no dia-a-dia.

\section{Preferência musical e correlatos}

A música está presente nas mais diversas situações cotidianas, desempenhando diferentes papéis a partir de interesses expostos (Pais, 1998; Rentfrow \&
Gosling, 2003; Tekman \& Hortaçsu, 2002). Pode-se verificar, conseqüentemente, que está relacionada com diversos construtos e comportamentos específicos. Por exemplo, buscando examinar a relação entre características da personalidade e questões do desenvolvimento de grupos ligados a estilos musicais, Schwartz e Fouts (2003) mostraram que os jovens usam a música para resistir à autoridade em todos os níveis, afirmar sua personalidade, desenvolver relações de pares e de compromisso romântico e aprender sobre assuntos que muitas vezes nem os seus pais nem a escola estão aptos a discutir.

Tekman e Hortaçsu (2002) iniciam seu artigo sobre música e identidade reportando a influência da identificação com estilos musicais na configuração da identidade pessoal e social. Segundo tais autores, os indivíduos utilizam a música para propósitos avaliativos e processos de identificação grupal, o que, conseqüentemente, atesta a importância desse veículo de comunicação de massa nas diversas situações em que o jovem se encontra no dia-a-dia, podendo influenciar sua escolha do vestuário, bem como sua atração ou rejeição por determinados grupos.

De acordo com Pais (1998), a música, os gêneros musicais específicos, assim como a aparência ou a linguagem, são "elementos simbólicos" que dão coerência interna aos grupos, servindo para formar e consolidar uma identidade grupal. Nesta análise, a música é considerada um "signo juvenil geracional", pois seria universal aos grupos de jovens. O mesmo autor afirma que preferências musicais são acompanhadas de atitudes específicas que reforçam e até ultrapassam os gostos musicais. Desse modo, a atração por diferentes tipos de música deriva, provavelmente, do fato de jovens selecionarem esses estilos musicais em função de determinados aspectos de suas vidas, no âmbito real ou idealizado.

Além das variáveis previamente tratadas, pode-se observar, na literatura, que a preferência musical também está relacionada com diversos comportamentos ou fatores de risco. O heayy metal, o rap e o punk representam em suas letras sentimentos de rejeição e desafio à autoridade, comportamentos anti-sociais e hiperssexualidade (Schwartz \& Fouts, 2003), podendo o mesmo, por certo, ser atribuído ao funk nacional, por destacar o sexo, a violência e o cotidiano de enfrentamento nas favelas (Dayrell, 2002).

Schwartz e Fouts (2003) ainda verificam que a preferência por esses gêneros ou estilos musicais pode ocorrer por uma combinação entre os temas usados nas músicas e as características dos ouvintes, que nesse aspecto podem se mostrar como buscadores de sensações, anti-sociais e pouco sensíveis ou românticos. Weisskirch e Murphy (2004), nesse sentido, verificaram, entre estudantes universitários, que aqueles que 
apresentaram maiores pontuações no Inventário de Busca de Sensacōes foram os que mostraram maior preferência por heary metal, punk, reggae e ska. Por outro lado, foi verificado que as pontuações nesse inventário se correlacionaram inversamente com a preferência por rithym and blue $(\operatorname{R} \mho B)$ e pop rock.

Outros estudos afirmam a existência de uma correlação direta e significativa entre preferência por estilos alternativos/anticonvencionais (por exemplo, rap, heary metal, reggae, punk) e comportamentos e atitudes socialmente desviantes entre jovens e adolescentes (Lacourse, Claes \& Villeneuve, 2001; McNamara \& Ballard, 1999; Miranda \& Claes, 2004; North, Desborough \& Skarstein, 2005; Pimentel, Gouveia \& Vasconcelos, 2005). Estes reportam relações entre preferência musical, considerando em geral rap e heavy metal, e vários fatores e comportamentos de risco, como atitudes positivas em relação a maconha, uso de drogas, suscetibilidade ao suicídio, comportamento imprudente no trânsito (como dirigir intoxicado e/ou em alta velocidade), comportamento sexual de risco e vandalismo, além de dificuldade nas relações parentais, depressão e sentimentos de alienação (para uma revisão, ver Hogan \& cols., 1996; Villani, 2001).

Em sua análise qualitativa dos estilos rap e funk, Dayrell (2002) argumenta que, por intermédio da música, os jovens experimentam a possibilidade de uma atividade com sentido, recusando-se a aceitar sua sujeç̧ão às alternativas que thes são postas. No caso específico do rap, acrescenta esse autor, produz-se um discurso de denúncia da injustiça e da opressão a partir do seu enraizamento nos guetos negros urbanos. Portanto, seria este estilo uma crônica da realidade da periferia, figurando inclusive como uma forma de intervenção social, embora em outros moldes, isto é, por meio da linguagem poética, do corpo e do lazer, impregnando o discurso com uma visão que educa e transforma a periferia.

É importante a ressalva de que os estilos previamente apresentados são os que mais preocuparam a opinião pública (Binder, 1993; Hogan \& cols., 1996; McNamara \& Ballard, 1999). Portanto, foram os que mais capturaram a atenção dos pesquisadores, sendo, pois, importante que se realizem estudos sobre outras dimensões de preferência. Essa necessidade, como advertem Schwartz e Fouts (2003), é especialmente verdadeira para estilos musicais lights, como pop, dance $\mathrm{e}$ ecléticos.

Em resumo, percebe-se que existem diferentes estilos musicais, alguns dos quais mais preponderantemente estudados como explicação de comportamentos juvenis, sobretudo aqueles que rompem normas sociais. Contudo, os estudos têm enfocado um ou outro estilo, considerando-os separadamente, sem avaliar as dimensões subjacentes (Rentfrow \& Gosling, 2003). Nesse sentido, é pertinente todo empreendimento para desenvolver medidas de preferência musical, e isso se faz ainda mais eminente no cenário nacional, onde nenhuma está ainda disponível. Seguramente, contar com medidas dessa natureza seria fundamental para promover os estudos no âmbito da psicologia social da música, área ainda incipiente. $\mathrm{O}$ presente estudo, vale enfatizar, tem justamente o objetivo de construir e conhecer os parâmetros psicométricos (estrutura fatorial e consistência interna) de uma Escala de Preferência Musical. Nesse sentido, consideram-se diversos estilos musicais, testando as dimensões resultantes através de modelagem por equações estruturais.

\section{Método}

\section{Participantes}

Participaram da pesquisa 480 estudantes do ensino médio, provenientes de duas escolas públicas $(48,1 \%)$ e duas privadas $(51,9 \%)$ de João Pessoa, sendo a maioria do sexo feminino $(55,1 \%)$. As escolas públicas ficavam uma no centro e outra na periferia, e as escolas privadas ficavam em área nobre da cidade, em bairro próximo à praia. Do total de participantes, $173(36 \%)$ estavam matriculados no primeiro ano, $146(30,5 \%)$ no segundo e $161(33,5 \%)$ no terceiro. A maioria $(95,4 \%)$ apresentou idades entre 13 e 18 anos $(M=16,2$; $\mathrm{DP}=1,60$; amplitude de 13 a 28), reportou ser solteira $(95,8 \%)$ e pertencer a família de classe socioeconômica média $(58,2 \%)$ ou média-baixa $(27,8 \%)$. Esta é uma amostra não-probabilística, isto é, de conveniência, tendo sido considerados os estudantes que, contatados em sala de aula, concordaram em fazer parte do estudo. Com o propósito de elaborar um modelo de medida e testá-lo em amostra independente, decidiu-se dividir aleatoriamente esta amostra em duas, com igual número de participantes:

Amostra 1. Os 240 participantes dessa subamostra se dividiram entre estudantes da rede pública $(46,7 \%)$ e privada (53,3\%), matriculados na primeira $(37,5 \%)$, segunda $(28,3 \%)$ ou terceira $(34,2 \%)$ série, sendo a maioria mulher $(54,8 \%)$, solteira $(95,8 \%)$ e de classe socioeconômica média $(57,5 \%)$ ou médiabaixa $(29,6 \%)$. Sua idade média foi de 16,3 anos (DP = 1,73; amplitude de 13 a 28), a maioria situando-se entre os 13 e 18 anos (94,6\%).

Amostra 2. Os 240 estudantes que compuseram essa amostra estavam matriculados na rede pública $(49,6 \%)$ ou privada $(50,4 \%)$, cursando a primeira $(34,6 \%)$, segunda $(32,5 \%)$ ou terceira $(32,9 \%)$ série, sendo a maioria do sexo feminino $(55,8 \%)$, solteira $(95,8 \%)$ e de classe socioeconômica média $(59 \%)$ ou 
média-baixa (25,9\%). A maioria se situou entre os $13 \mathrm{e}$ 18 anos (96,3\%), com idade média de 16,2 anos (DP=1,45; amplitude de 13 a 24).

Posteriormente, verificou-se a equivalência destas amostras em relação às principais variáveis demográficas: sexo $\left[\chi^{2}(1)=0,02, \mathrm{p}=0,89\right]$, idade $[t$ $(477)=0,95, \mathrm{p}=0,34]$, estado civil $\left[\chi^{2}(3)=1,90, \mathrm{p}=0,59\right]$, classe socioeconômica $[t(477)=1,63, \mathrm{p}=0,10]$, escola $\left[\mathcal{X}^{2}(1)=0,41, \mathrm{p}=0,52\right]$ e série $\left[\mathcal{X}^{2}(2)=1,02, \mathrm{p}=0,60\right]$. Portanto, pode-se admitir que são amostras equivalentes quanto a essas características demográficas centrais.

\section{Instrumento}

Os participantes receberam um livreto com um bloco de instrumentos, entre os quais a Escala de Preferencia Musical (EPM) e perguntas demográficas. Considerando os propósitos deste estudo, unicamente se mencionará esta medida. Nesse caso, seguindo recomendação de Pasquali (2003), seguiram-se duas etapas principais para sua elaboração:

Análise de conteído. Essa análise, também identificada como teórica, considerou a participação de quatro juízes, os quais deveriam averiguar a pertinência dos estilos listados como representantes dos adolescentes da cultura paraibana. Intentou-se abarcar estilos que, teoricamente, eram mais conhecidos dos adolescentes do contexto em que esta pesquisa se insere. Foi intencional também a utilização de estilos gerais, não se considerando os subgêneros $\mathrm{e}$ as ramificações que poderiam surgir desses estilos. A retenção dos itens na escala era considerada com um mínimo de $75 \%$ de acordo entre os juízes. Este procedimento permitiu identificar um total de 13 estilos musicais: rap/hip-hop, sertanejo, MPB, pagode, pop music, punk/hard core, funk, heavy metal, forró, samba, música clássica, música religiosa e reggae.

Para cada um desses estilos musicais foram apresentados três exemplos de bandas e/ou músicos. Por exemplo, heavy metal (Black Sabbath, Iron Maiden e Metallica), música clássica (Beethoven, Mozart e Chopin), rap (Beastie Boys, Faces do Subúrbio e Public Enemy), música religiosa (Padre Marcelo, Aline Barros e Melissa). Os participantes deveriam ler o tipo de estilo, tomar em conta os exemplos e responder o quanto gostavam de cada um. Para isso, apresentou-se uma escala de resposta de cinco pontos, com os extremos $1=$ detesto e $5=$ gosto muito.

Análise semântica. Essa etapa contou com a participação de dez estudantes da sétima série do ensino fundamental da rede pública. Após sua liberação das atividades escolares por parte dos professores correspondentes, estes foram reunidos em um único grupo, ocupando um ambiente cedido pela direção da escola. A todos foi indicado que a participação seria voluntária, sendo possível deixar o estudo se desejassem. Procurou-se assegurar seu anonimato, evitando que escrevessem o nome no questionário. Sua tarefa se constituiu em ler com atenção as instruções de como responder a escala, comprovar a clareza do seu conteúdo (itens/estilos musicais) e a viabilidade de se empregar a escala de resposta proposta. As dúvidas e/ou dificuldades deveriam ser anotadas, para depois ser discutidas no grupo. Após essa análise, concluiu-se que o instrumento poderia ser adequadamente compreendido e respondido pelos potenciais participantes do estudo. Para isso, contou-se com a versão experimental da Escala de Preferência Musical, composta por 13 itens, que foi posteriormente aplicada nas amostras previamente descritas.

\section{Procedimento}

Para a realização da coleta de dados foram contatadas as direções das escolas escolhidas por conveniência, procurando-se obter permissão para a aplicação dos questionários. Após o consentimento da direção, a aplicação foi efetuada por três bolsistas de Iniciação Científica (IC) do curso de Psicologia de uma instituição pública, supervisionados pelos autores deste artigo. Previamente, realizou-se um treinamento com os bolsistas, indicando que se limitassem às instruções da escala, esclarecendo os respondentes quanto à forma, mas não ao conteúdo da medida. As salas de aula foram previamente escolhidas e as informações básicas para o andamento do processo de coleta foram expressas oralmente aos participantes. Estes responderam individualmente, porém em ambiente coletivo de sala de aula. Os colaboradores estiveram presentes durante a aplicação para esclarecer eventuais dúvidas quanto à forma de responder. Depois de coletados e verificados os questionários respondidos, foram dirigidos os agradecimentos pela colaboração da turma. Em média, 20 minutos foram suficientes para concluir sua participação.

\section{Análises estatísticas}

Tanto a entrada dos dados como as análises estatísticas iniciais foram realizadas com o SPSS (Statistical Package for the Social Science) para Windows (versão 11). Foram calculadas estatísticas descritivas (média, tendência central, dispersão), análise de componentes principais (PCA) e alfa de Cronbach (consistência interna). Para comprovação do modelo multidimensional da EPM, realizou-se uma análise fatorial confirmatória (CFA) com o pacote estatístico AMOS 4. Nesse caso, considerou-se a matriz de covariância, tendo sido adotado o estimador ML (Maximum Likelihood). 
Essa estatística oferece vários indicadores de ajuste do modelo teórico aos dados empíricos, sendo aqui considerados os seguintes (Byrne, 1989, 2001; Joreskög \& Sörbom, 1989; Tabachnick \& Fidell, 2001): (1) a razão $\chi^{2} /$ g.l. (qui-quadrado / graus de liberdade), admitindo-se um valor de até 5 como indicativo de ajustamento adequado; (2) Goodness-of-Fit Index (GFI) e Adjusted Goodness-of-Fit Index (AGFI), cujos valores variam de 0 a 1 , com aqueles próximos a 0,90 indicando ajustamento satisfatório. Análogo ao $\mathrm{R}^{2}$ em regressão múltipla, este indica a proporção de variância-covariância nos dados explicada pelo modelo; (3) o CFI é um índice comparativo, adicional, de ajuste ao modelo, com valores mais próximos de 1 indicando melhor ajuste, com 0,90 sendo a referência para aceitar o modelo; e (4) o RMSEA, que se baseia nos residuais, sendo melhor quanto mais próximo este índice for de zero (melhor o ajuste do modelo hipotético aos dados); admitem-se valores de até 0,10 , porém tem-se geralmente em conta o ponto de corte de 0,08. Foi também realizada uma análise de perfil (profile analysis) através do comando MANOVA e calculadas correlações de Pearson.

\section{Resultados}

\section{Análises preliminares}

Nessa seção se descrevem os resultados com relação às porcentagens da preferência musical dos adolescentes para os estilos que compõem a escala.
Consideraram-se apenas as pontuações de favorabilidade (preferência), isto é, 4 (gostar) e 5 (gostar muito), para a amostra total de participantes. Organizando-se as preferências por ordem decrescente de importância, observou-se o seguinte perfil: forró (50,6\%), MPB (46,1\%), música religiosa (43\%), pop music (39,5\%), samba $(33,4 \%)$, pagode $(33,2 \%)$, reggae $(33,2 \%)$, heavy metal (25,9\%), funk (20,8\%), punk/hardcore $(19,9 \%)$, música clássica $(17,3 \%)$, música sertaneja $(17,2 \%)$ e, finalmente, rap $(15,9 \%)$. Em resumo, percebe-se que os participantes desta pesquisa preferem músicas mais regionais e convencionais, a exemplo do forró e da MPB.

\section{Análise exploratória da EPM}

Nesta oportunidade foi considerada a primeira amostra do estudo (amostra 1). Para a análise dos parâmetros psicométricos da EPM proposta, buscou-se previamente conhecer o índice $\mathrm{KMO}(0,77)$ e o Teste de Esfericidade de Bartlett $\left[\chi^{2}(78)=930,45, \mathrm{p}<0,001\right]$, os quais podem ser avaliados como aceitáveis, justificando a realização de uma análise de componentes principais (PCA) (ver Tabachnick \& Fidell, 2001). Assumindo o critério de Kaiser, isto é, eigenvalue (valor próprio) maior que 1 , até quatro componentes podem ser retirados, explicando conjuntamente $64,5 \%$ da variância total. Alternativamente, procurou-se atestar essa solução inspecionando a distribuição gráfica dos valores próprios (scree plot), que é apresentada na Figura 1 a seguir.

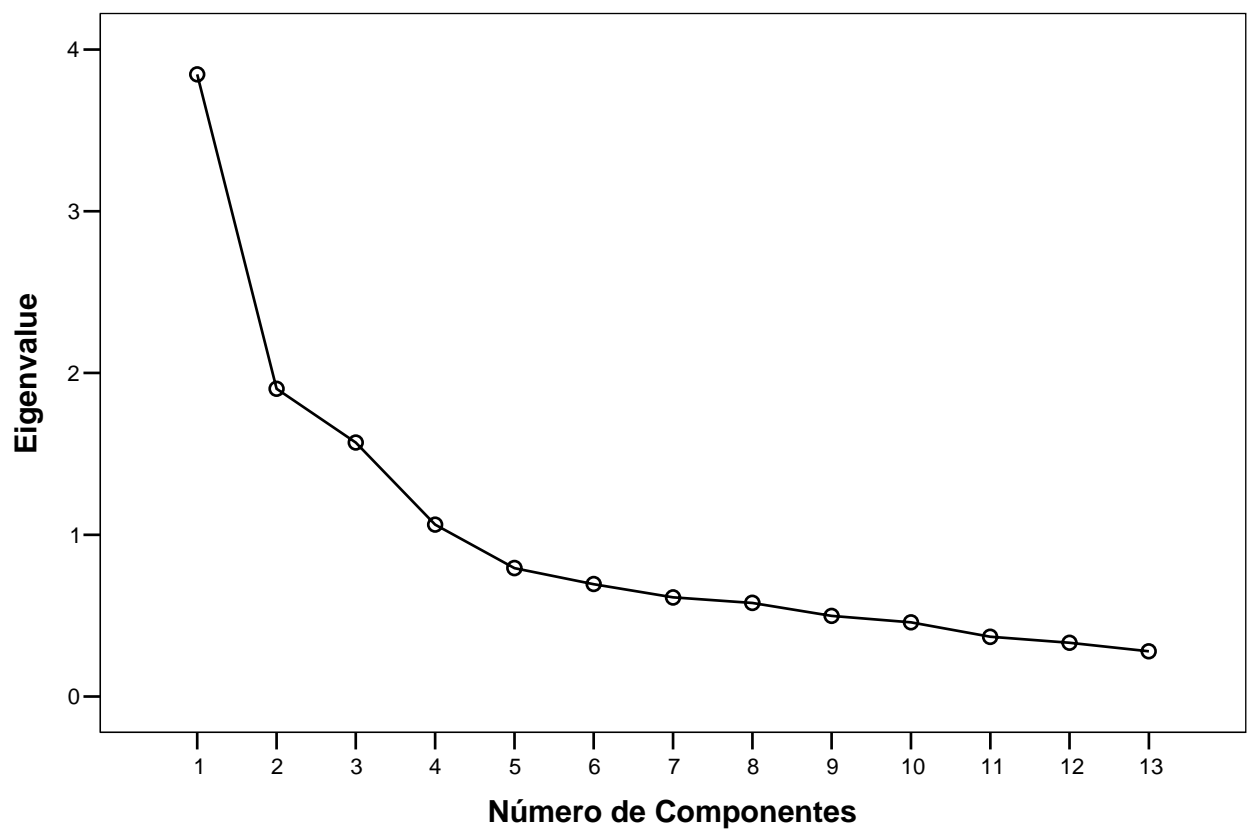

Figura 1 - Distribuição gráfica dos componentes da Escala de Preferência Musical 
Nessa figura foi desenhada uma linha mostrando que, a partir do quarto componente, os valores próprios não se diferenciam drasticamente entre si, aproximando-se de uma linha paralela ao eixo horizontal. Portanto, optou-se por uma solução com quatro componentes, que permitem contemplar os estilos musicais tratados previamente. Essa solução é sumarizada na Tabela 1.

Tabela 1 - Análise de componentes principais da Escala de Preferência Musical

\begin{tabular}{|c|c|c|c|c|}
\hline \multirow{2}{*}{ Estilos musicais } & \multicolumn{4}{|c|}{ Componentes } \\
\hline & I & II & III & IV \\
\hline Funk & $0,86^{*}$ & 0,25 & $-0,30$ & 0,01 \\
\hline Pagode & $0,80^{*}$ & $-0,06$ & $-0,01$ & 0,09 \\
\hline Forró & $0,74 *$ & $-0,12$ & $-0,07$ & 0,09 \\
\hline Samba & $0,63^{*}$ & $-0,01$ & $0,50^{*}$ & $-0,28$ \\
\hline Reggae & 0,19 & $0,78^{*}$ & 0,28 & 0,14 \\
\hline Rap, hip-hope & 0,12 & $0,77^{*}$ & $-0,05$ & 0,02 \\
\hline Punk & $-0,21$ & $0,67^{*}$ & 0,04 & $-0,14$ \\
\hline Heavy metal & $-0,21$ & $0,58^{*}$ & $-0,15$ & $-0,01$ \\
\hline MPB & 0,01 & 0,07 & $0,86^{*}$ & $-0,07$ \\
\hline Clássica & $-0,34$ & 0,02 & $0,80 *$ & 0,21 \\
\hline Pop music & $-0,12$ & $-0,04$ & 0,03 & $0,83^{*}$ \\
\hline Gospel & 0,19 & 0,14 & $-0,01$ & $0,81 *$ \\
\hline Sertaneja & 0,33 & $-0,18$ & 0,11 & $0,41 *$ \\
\hline Número de itens & 4 & 4 & 3 & 3 \\
\hline Eigenvalue & 3,85 & 1,96 & 1,56 & 1,06 \\
\hline \% Variância explicada & 29,6 & 14,6 & 12,1 & 8,2 \\
\hline$r_{\text {i.t }}$ (média corrigida) & 0,58 & 0,46 & 0,45 & 0,48 \\
\hline Alfa de Cronbach & 0,77 & 0,67 & 0,63 & 0,66 \\
\hline
\end{tabular}

*Cargas fatoriais consideradas satisfatórias para interpretar o fator, $a_{i . f}>|0,40|$. Rotação promax, fixando a extração de quatro fatores.

Com o fim de interpretar os respectivos componentes, considerou-se que o item deveria apresentar saturação (carga fatorial) igual ou superior a $|0,40|$ no seu componente respectivo. A descrição e a interpretação de cada um dos componentes são feitas como segue:

Componente I - Este primeiro componente, com valor próprio de 3,85, agrupou quatro itens (estilos musicais), a saber: funk, pagode, forró e samba, podendo ser denominado de música de massa, por conter estilos que trazem em suas músicas mensagens que visam atingir um público cada vez mais geral e diversificado. Elementos que compõem este gênero musical podem ser vistos como mais aliados às crenças e aos costumes populares. Pode-se notar a maior e menor saturações correspondendo, respectivamente, aos estilos funk $(0,86)$ e samba $(0,63)$. Como se observa, este componente explica $29,6 \%$ da variância total, apresentando um índice de consistência interna (alfa de Cronbach, $\alpha$ ) de 0,77. A correlação item-componente média corrigida ( $\left.r_{i . t}\right)$, indicação da homogeneidade da escala, situou-se em 0,58 , variando de 0,49 a 0,71 .
Componente II - Tendo um valor próprio de 1,90 , este segundo componente reuniu quatro itens / estilos musicais: reggae, rap, punk e beavy metal. Foi rotulado como representando a dimensão alternativa, agrupando estilos anticonvencionais, apreciados em tribos urbanas, que podem ter ainda ritmo acelerado e músicas com teor agressivo e de contestação política. A maior e menor saturações corresponderam aos estilos reggae $(0,78)$ e heavy metal $(0,58)$, respectivamente. Este componente responde por $14,6 \%$ da variância total, com alfa de Cronbach de 0,67 ; a correlação item-componente média corrigida $\left(\mathrm{r}_{\mathrm{i} . t}\right)$ ficou em 0,46 , variando de 0,34 a 0,62 .

Componente III - Este terceiro componente, com valor próprio de 1,57, agregou os seguintes estilos musicais: MPB, música clássica e samba, cujas saturações para o primeiro e último estilos foram, respectivamente, 0,86 e 0,50. Considerando o conteúdo das músicas deste componente, pode-se denominá-lo refinado, por apresentar estilos mais clássicos, mais suaves quanto às melodias, além de estarem relacionados com maior status social e educacional. Em seus ritmos e letras pode ser observado um apuro técnico, um cuidado com palavras e 
arranjos. Este componente explicou 12,1\% da variância total, tendo apresentado índice de consistência interna (Alfa de Cronbach, $\alpha$ ) de 0,63. A ri.t foi de 0,45, variando de 0,38 a 0,57 .

Componente IV - Este quarto e último componente, com valor próprio de 1,06, foi representado pelos estilos musicais (saturação entre parênteses): pop music $(0,83)$, música religiosa $(0,81)$ e música sertaneja $(0,41)$. É possível denominá-lo de convencional, pois reúne estilos musicais que transmitem em suas letras um padrão de comportamentos socialmente aceitos, além de tratarem de relações interpessoais e sentimentos como o amor e a paixão. Este foi responsável pela explicação de $8,2 \%$ da variância total, apresentando um $\alpha$ de 0,66; a correlação item-componente média corrigida $\left(\mathrm{r}_{\mathrm{i} . t}\right)$ foi de 0,48 , variando de 0,45 a 0,53 .

A maioria desses componentes se correlacionou com cada outro, indicando uma estrutura em que não se excluem interesses ou preferências musicais. Especificamente, música de massa se correlacionou inversamente com o componente alternativo $(\mathrm{r}=-0,25)$, e diretamente com o refinado $(\mathrm{r}=0,33)$ e convencional $(\mathrm{r}=0,58) ; \quad \mathrm{o}$ componente alternativo apresentou-se inversamente correlacionado ao convencional $(\mathrm{r}=-0,35)$; e, por fim, o componente refinado correlacionou-se diretamente ao convencional $(\mathrm{r}=0,18)$ (todas as correlações foram estatisticamente significativas a um $\mathrm{p}<0,01$ ). Neste contexto, destaca-se que o componente alternativo se correlacionou negativamente com todos os demais.

Em resumo, pelos critérios estatísticos empregados, tendo-se em conta também a interpretabilidade da solução, foram identificados quatro componentes de estilos musicais. Considerando, todavia, que a análise efetuada (componentes principais) tem limitações referenciadas na literatura, decidiu-se realizar uma análise fatorial confirmatória (CFA). Esta apresenta vantagens evidentes com relação à PCA (Pasquali, 2003; Tabachnick \& Fidell, 2001).

\section{Análise fatorial confirmatória da EPM}

Para testar a estrutura multidimensional previamente descrita para a EPM, efetuou-se uma CFA, considerando a matriz de covariância e empregando o estimador ML. Nesse caso, teve-se em conta a segunda amostra do estudo (amostra 2). As saturações dos itens nos fatores teóricos respectivos foram definidas de acordo com os resultados da análise de componentes principais, sendo fixado em $1 \mathrm{o}$ item com maior saturação observada em cada fator (Tabela 1). O modelo final pode ser verificado a seguir.

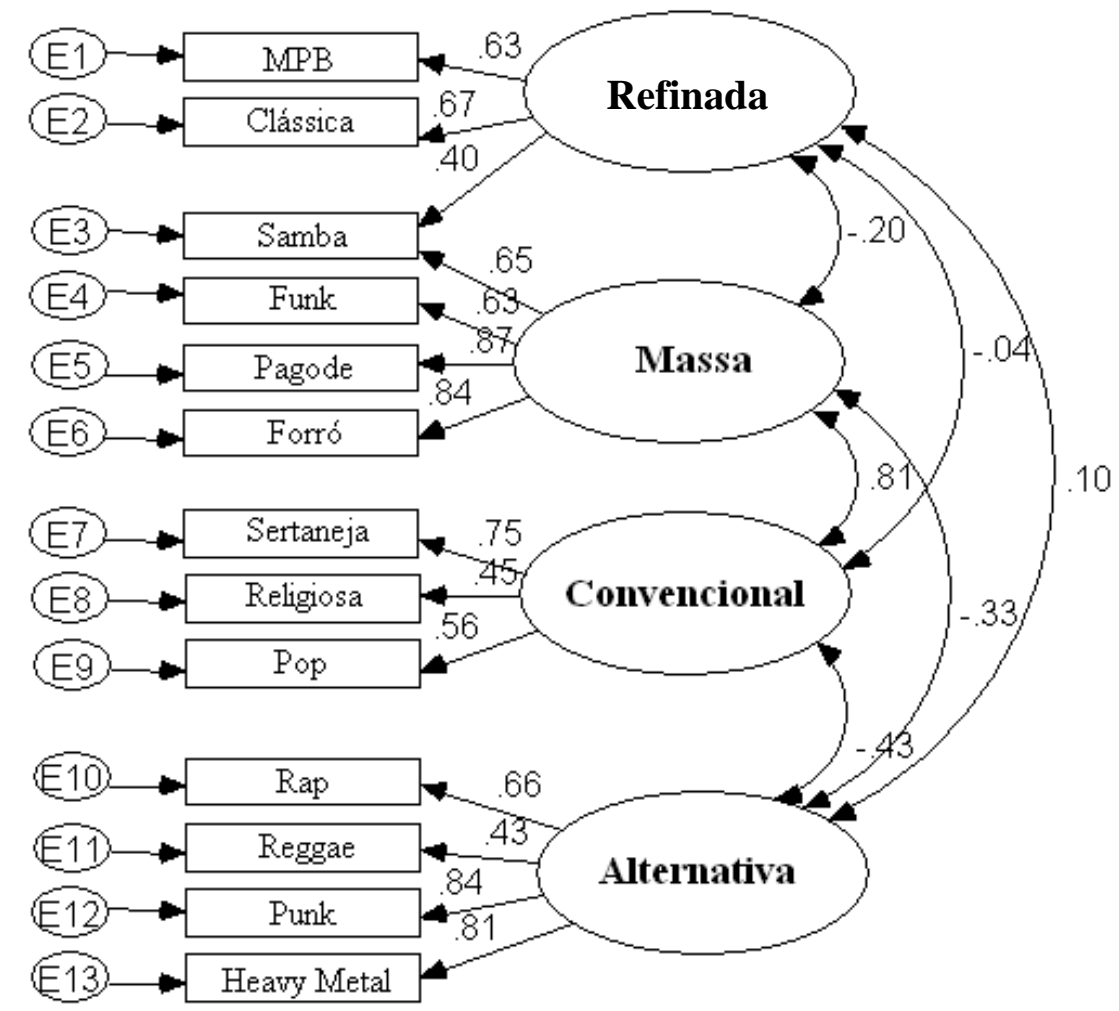

Figura 2 - Comprovação da estrutura fatorial da Escala de Preferência Musical 
Todas as saturações (lambdas, $\lambda$ ) foram estatisticamente diferentes de zero $(t>1,96, p<0,05)$. O modelo teórico, sem restrições, apresentou os seguintes indicadores de ajuste: $\chi^{2}(58)=192,51, \mathrm{p}<0,001, \chi^{2} / \mathrm{gl}=3,32$, $\mathrm{GFI}=0,89$, AGFI $=0,83, \quad \mathrm{CFI}=0,88$ e $\mathrm{RMSEA}=0,099$ (intervalor de confiança, IC $90 \%=0,083-0,114$ ). Contudo, tendo em conta os índices de modificação para os termos de erro (E), considerando igualmente sua pertinência teórica, ao serem fixadas as covariâncias entre os erros E4 (funk) e E6 (forró), e E10 (rap) e E11 (reggae), estes índices se mostraram algo melhores: $\chi^{2} \quad(56)=165,77, \mathrm{p}<0,001$, $\chi^{2} / \mathrm{gl}=2,96, \quad \mathrm{GFI}=0,91, \quad \mathrm{AGFI}=0,85, \quad \mathrm{CFI}=0,90 \quad \mathrm{e}$ RMSEA $=0,091(\mathrm{IC} 90 \%=0,075-0,107)$.

Considerando a amostra total de respondentes $(\mathrm{N}=480)$, foi realizada uma análise de perfil (MANOVA) 2 (sexo: masculino vs. feminino) x 2 (tipo de escola: pública $v$ s. privada), com um fator intra-sujeito de medidas repetidas (os quatro fatores da escala); as variáveis dependentes foram as médias de preferência em cada subescala, procurando verificar se os participantes diferiam nas dimensões de preferência musical e a influência do sexo e do tipo de escola neste construto. Foi observado que os participantes diferiram em termos das pontuações nas subescalas [lambda de Wilks=0,95, F $(3,473)=7,45 ; \eta^{2}$ parcial $\left.=0,05\right]$, com o teste Post Hoc de Bonferroni indicando diferença significativa $(\mathrm{p}<0,05)$ em relação às médias das dimensões Refinado $(M=2,85)$ e Alternativa $(M=2,61)$, e desta com Convencional $(M=2,82)$. Constatou-se ainda que o sexo do participante influenciou (15\% da explicação) sua preferência musical [lambda de Wilks=0,84, $\mathrm{F}(3,473)=28,83, \mathrm{p}<0,001$, $\eta^{2}$ parcial $\left.=0,15\right]$. Especificamente, observou-se que os participantes do sexo masculino mostraram menor preferência $(M=2,63, D P=0,97)$ do que os do sexo feminino $(\mathrm{M}=2,84, \mathrm{DP}=1,01)$ por música de massa; um padrão similar de diferença foi constatado em relação à preferência pelos estilos musicais refinado $(M=2,82$, $\mathrm{DP}=0,89$ e $\mathrm{M}=2,87, \mathrm{DP}=0,85$, respectivamente) e Convencional $(\mathrm{M}=2,44, \mathrm{DP}=0,89$ e $\mathrm{M}=3,19, \mathrm{DP}=0,94$, respectivamente). Contrariamente, os homens indicaram preferir em maior medida o estilo de música alternativa $(M=2,80, D P=0,97)$ do que o fizeram as mulheres $(M=2,42, \quad D P=0,86)$. Não se verificaram efeitos significativos do tipo de escola ou de sua interação com o sexo em relação à preferência musical. Finalmente, correlacionaram-se as dimensões de preferência musical com a classe socioeconômica percebida, não tendo sido verificada qualquer associação estatisticamente significativa.

\section{Discussão}

$\mathrm{Na}$ época em que a presente pesquisa foi delineada não foi encontrado nenhum instrumento que permitisse avaliar a preferência musical. Nesse sentido, o objetivo estabelecido foi justamente construir e conhecer os parâmetros psicométricos de uma escala para avaliar este construto. Os resultados fazem pensar que o mesmo foi alcançado. A EPM proposta se revelou multidimensional, como mostrou a PCA e se corroborou mediante o modelo de equações estruturais, com índices de ajuste que possibilitam concluir pela adequação do modelo aos dados (Figura 2). Posteriormente, porém, encontrou-se uma escala para apurar a preferência musical (Short Test of Music Preference - STOMP), desenvolvida no contexto estadunidense com estudantes universitários (Rentfrow \& Gosling, 2003). Essa medida e a que se apresentou aqui compartilham muitos aspectos, como a concepção acerca da multidimensionalidade do construto preferência musical e a inclusão de determinados estilos (por exemplo, rap, heavy metal, música clássica). Não obstante, em se tratando de algo com características emic, não poderia deixar de existir também elementos musicais específicos do contexto em que se inseriu o estudo (por exemplo, forró, MPB).

Para o presente estudo, intentou-se abarcar estilos que teoricamente eram mais conhecidos dos adolescentes da região do nordeste do Brasil, especificamente da Paraíba, considerando que os estilos variam muito inter e transculturalmente. Por exemplo, no Maranhão é possível que o reggae tenha outra conotação, aparecendo entre os estilos considerados música de massa. Foi intencional a utilização de estilos gerais, não se considerando uma grande quantidade de ramificações. Como se sabe, em diversas culturas surgem numerosos estilos que resultam de uma combinação de diversos outros (provavelmente neste momento mesmo estejam sendo criados outros tantos). Como endossa Pinker (1997), "as complexidades dos estilos musicais variam bastante conforme a época, as culturas e subculturas" (p. 554). Tendo isso em vista, seria realmente difícil abarcar essas diferenças entre as culturas numa única medida.

Pretendeu-se, assim, construir e averiguar a validade de construto (estrutura fatorial e consistência interna) de uma escala para mensurar a preferência musical em uma amostra com características específicas, sem contar com uma teoria específica e axiomatizada sobre o construto de interesse. Isso, certamente, constitui-se na maior limitação da pesquisa, uma dificuldade adicional para a elaboração de uma medida psicometricamente adequada. Além disso, há que se considerar que populações específicas têm conhecimentos especializados no tocante à música. Nesse sentido, os aspectos sociodemográficos, a valorização que se dá à educação musical em grupos 
sociais e em países distintos, coloca barreiras claras para se contar com uma única medida. Portanto, sempre será uma limitação potencial a não-inclusão de outros gêneros musicais. Considerando essas limitações, que ainda incluem gasto com tempo e recursos humanos e materiais, na presente pesquisa adotou-se um procedimento essencialmente empírico-intuitivo. Esses aspectos podem limitar o poder de generalização dos resultados, porém certamente não os invalidam.

Pela PCA foi possível observar que a EPM, como foi delineada, revelou-se multifatorial, agregando os itens/estilos musicais em quatro componentes: (1) música de massa; (2) alternativa; (3) refinado; e (4) convencional, com alfas de 0,77, 0,67, 0,63 e 0,66, respectivamente. É importante registrar ainda que esses três últimos coeficientes de precisão não podem ser tidos como ideais (Nunnally, 1991), mas devem ser considerados como adequados para fins de pesquisa, dada à natureza "ampla" (polimorfa) do construto (Clark \& Watson, 1995; Mueller, 1986). Adicionalmente, foi computado o alfa médio $(0,68)$ da escala, que também pode ser considerado aceitável (Tabachnick \& Fidell, 2001). Além disso, a homogeneidade dos fatores, avaliada através da correlação do item com o total do componente, foi de pelo menos 0,45 , que pode ser considerada forte (Clark \& Watson, 1995).

É igualmente importante ressaltar que, embora não se tenham observado índices de confiabilidade muito elevados, o número reduzido de itens que compõem cada componente ( 3 ou 4 itens) pode ser uma explicação a respeito. O alfa de Cronbach é fortemente influenciado pelo número de itens que compõem um componente, aumentando segundo este seja aumentado. Por exemplo, se for considerado o terceiro componente, que apresentou o menor alfa $(0,63)$, este coeficiente poderia chegar a 0,84 (ver Nunnally, 1991, p. 267) se fosse formado por dez itens, número que na prática tem sido indicado para definir uma escala ou um fator. No entanto, considerando a preferência musical, não seria recomendado incluir esta quantidade de itens (dispor de diversos subgêneros) numa medida, pois é preferível a utilização de gêneros musicais (Rentfrow \& Gosling, 2003), como no presente caso.

Os quatro fatores, com valores próprios todos maiores que 1, de acordo com a PCA, explicam conjuntamente mais da metade $(64,78 \%)$ da variância total das pontuações dos respondentes. Esse índice pode ser considerado como adequado para a explicação da estrutura fatorial resultante. Tal estrutura foi posteriormente confirmada em uma segunda amostra, na qual se efetuou uma CFA; os indicadores encontrados de ajuste do modelo, embora não sejam excepcionais, podem ser considerados como satisfatórios (Byrne, 2001; Joreskög \& Sörbom, 1989). A propósito, deve-se ter em conta a natureza do construto avaliado, não sendo pertinente uma avaliação restrita aos pontos de corte (cutoff); como observa Bollen (1989), esses pontos são arbitrários, sendo igualmente importante considerar os indicadores de ajuste do mesmo fenômeno em amostras independentes. Por exemplo, é possível que um CFI de 0,85 represente progresso em um campo em que o maior valor previamente observado foi 0,70. Esse aspecto justifica replicar a presente pesquisa, considerando participantes com características demográficas e de contextos diversos.

Apesar de não ter sido o objetivo principal deste trabalho, foram ainda calculadas as correlações entre os quatro componentes de preferência musical. Os resultados revelaram que o componente alternativo se correlacionou negativamente com todos os demais. Este aspecto é bastante compreensível, haja vista que a preferência pelos estilos desta dimensão representa mais um aspecto diferenciador de culturas juvenis (Pais, 1998; Tekman \& Hortaçsu, 2002). Portanto, apreciar estilos como o heavy mental ou o punk dão uma identidade própria e peculiar ao indivíduo, diferenciando-o em razão da sua potencial inserção em um grupo que expressa aversão ou pelo menos apatia em relação a outros estilos musicais, principalmente aqueles nomeados aqui como convencionais (pop music, música religiosa e música sertaneja). Poder-se-ia mesmo falar em preconceito com base na preferência musical ou simplesmente preconceito musical. Este pode ser um campo de interesse para a psicologia social de grupos. As pessoas que formam os grupos também podem se diferenciar simplesmente pelo sexo, masculino ou feminino, como se viu no presente caso, e de acordo com outros estudos o grupo dos adolescentes tende a gostar mais de músicas agitadas e menos de músicas convencionais, em comparação com as adolescentes (McNamara \& Ballard, 1999; Pimentel, Gouveia \& Vasconcelos, 2005), mesmo não tendo se verificado uma diferença de grande magnitude, de acordo com a análise realizada (Dancey \& Reidy, 2006; Garson, 2003).

Em resumo, a despeito das limitações da escala proposta, mas tendo-se em conta que se trata de uma primeira versão, além da própria complexidade do construto, pode-se considerá-la como satisfatória. Nesse sentido, verificar a validade convergente e divergente dessa medida seria igualmente oportuno no futuro. Por outro lado, sugere-se que em novos estudos sejam considerados outros estilos musicais, acrescentados novos itens (por exemplo, blues, ją\%, música eletrônica). Isso pode ser favorável à precisão (alfa de Cronbach) 
dessa medida. Contudo, em razão dos resultados antes descritos, pensa-se que o presente artigo representa uma contribuição, ou pelo menos uma aproximação, à temática da preferência musical, tendo oferecido uma medida que poderá ser empregada em pesquisas futuras em que se objetive, por exemplo, conhecer a relação da preferência musical com diversas variáveis, como os traços de personalidade, valores e atitudes. Seguramente, esses e outros empreendimentos que se seguirão serão decisivos para conhecer o impacto que a preferência musical exerce no comportamento das pessoas, principalmente dos jovens. Esta é uma área de pesquisa promissora, embora carente de evidências empíricas no âmbito da psicologia social e da personalidade (Rentfrow \& Gosling, 2003).

\section{Referências}

Abdounur, O. J. (2002). Matemática e música: O pensamento analógico na construção de significados. São Paulo, SP: Escrituras.

Aristóteles (1973). Poética. São Paulo: Abril Cultural.

Ballard, M. E., Dodson, A. R. \& Bazzini, D. G. (1999). Genre of music and lyrical content: Expectation effects. The Journal of Genetic Psychology, 160(4), 476-487.

Binder, A. (1993). Constructing racial rhetoric: Media depictions of harm in heavy metal and rap music. American Sociological Review, 58(6), 753-767.

Bollen, K. A. (1989). Structural equations with latent variables. New York: Wiley.

Byrne, B. M. (1989). A primer of LISREL: Basic applications and programming for confirmatory factor analytic models. Nova Iorque: Springer-Verlag.

Byrne, B. M. (2001). Strutural equation modeling with Amos: Basic concepts, applications, and programming. Londres: Lawrence Erlbaum.

Clark, L. A. \& Watson, D. (1995). Constructing validity: Basic issues in objective scale development. Psychological Assessment, 7(3), 309-319.

Dancey, C. P. \& Reidy, J. (2006). Estatística sem matemática para psicologia. Porto Alegre, RS: Artmed.

Dayrell, J. (2002). O rap e o funk na socialização da juventude. Educação e Pesquisa, 28, 117-136.

Farnsworth, P. E. (1969). Social psychology of music. Ames: Iowa State University Press.

Garson, G. D. (2003). PA 765 Statnotes: An online textbook. Obtido em 8 de setembro de 2007 do World
Wide Web: http://www2.chass.ncsu.edu/garson/ pa765/statnote.htm.

Hargreaves, D. J. \& North, A. C. (1997). The social psychology of music. Oxford: Oxford University Press.

Hobsbawn, E. (2004). História social do jaž. São Paulo: Paz e Terra.

Hogan, M., Bar-on, M., Beard, L., Corrigan, S., Holroyd, H. J., Sherry, S. N., Shifrin, D. \& Strasburger, V. (1996). Impact of music lyrics and music videos on children and youth. Pediatrics, 98(6), 1219-1221.

Joresköb, K. \& Sörbom, D. (1989). Lisrel 7 user's reference guide. Mooresville: Scientific Software.

Lacourse, E., Claes, M. \& Villeneuve, M. (2001). Heavy metal music and adolescent suicidal risk. Journal of Youth and Adolescence, 30(3), 321-331.

McNamara, L. \& Ballard, M. E. (1999). Resting arousal, sensation seeking, and music preference. Genetic, Social, and General Psychology Monographs, 125(3), 229250.

Miranda, M. C. \& Claes, M. (2004). Rap music genres and deviant behavior in French-Canadian adolescents. Journal of Youth and Adolescence, 33(2), 113-122.

Mueller, D. J. (1986). Measuring social attitudes: A bandbook for researchers and practitioners. Nova Iorque, NY: Teachers College Press.

North, A. C., Desborough L. \& Skarstein, L. (2005). Musical preference, deviance, and attitudes towards music celebrities. Personality and Individual Differences, 38(8), 1903-1914.

Nunnally, J. C. (1991). Teoría psicométrica. México, DF: Trillas.

Outhwaite, W. \& Bottomore, T. (1996). Dicionário do pensamento social do século XX. Rio de Janeiro: Jorge Zahar.

Pais, J. M. (1998). Culturas juvenis. Lisboa, PO: Imprensa Nacional Casa da Moeda.

Pasquali, L. (2003). Psicometria: teoria dos testes na psicologia e na educação. Petrópolis, RJ: Vozes.

Pimentel, C. E., Gouveia, V. V. \& Vasconcelos, T. C. (2005). Preferência musical, atitudes e comportamentos antisociais entre estudantes adolescentes: um estudo correlacional. Estudos de Psicologia, Campinas, 22(4), 401-411.

Pinker, S. (1997). Como a mente funciona. São Paulo, SP: Companhia das Letras. (Originalmente publicado em 1954). 
Platão (1993). A República. Lisboa: Fundação Calouste Gulbenkian.

Rentfrow, P. J. \& Gosling, S. D (2003). The do re mi's of everyday life: The structure and personality correlates of music preference. Journal of Personality and Social Psychology, 84(6), 226-236.

Schell, K. R. \& Westefeld, J. S. (1999). Heavy metal and adolescent suicidality: An empirical investigation. Adolescence, 34(134), 253-273.

Schwartz, K. D. \& Fouts, G. T. (2003). Music preferences, personality style, and developmental issues of adolescents. Journal of Youth and Adolescence, 32(3), 205-221.

Tabachnick, B. G. \& Fidell, L. S. (2001). Using multivariate statistics. California: Allyn \& Bacon.

Tekman, H. G. \& Hortaçsu, N. (2002). Music and social identity: Stylistic identification as a response to musical style. International Journal of Psychology, 37(5), 227-285.

Villani, S. (2001). Impact of media on children and adolescents: A 10-year review of the research. Journal of American Academic of Child Adolescent Psychiatry, 40(4), 392-401.

Weisskirch, R. S. \& Murphy, L. C. (2004). Friends, porn, and punk: Sensation seeking in personal relationships, internet activities, and music preference among college studentes. Adolescence, 39(154), 189201.

Recebido em março de 2006 Reformulado em setembro de 2007 Aprovado em setembro de 2007

Sobre os autores:

Carlos Eduardo Pimentel é mestre em Psicologia Social (2004) pela Universidade Federal da Paraíba. Atualmente é professor assistente I do Curso de Psicologia da Universidade Tiradentes. Seus principais interesses de pesquisa incluem a psicologia da mídia, psicologia da música e das atitudes e comportamentos anti-sociais.

Valdiney V. Gouveia é doutor em Psicologia Social (1998) pela Universidade Complutense de Madri. Atualmente é professor adjunto IV na Universidade Federal da Paraíba e bolsista de Produtividade em Pesquisa do CNPq - Nível 1C. Alguns dos tópicos aos quais tem se dedicado são: valores humanos, atitudes ambientais, comportamentos pró e anti-sociais, individualismo-coletivismo e avaliação psicológica (construção e adaptação de escalas e testes).

Viviany Silva Pessoa é mestranda em Psicologia pela Universidade Federal do Rio Grande do Norte. Tem experiência na área de Psicologia, com ênfase em Psicologia Ambiental e Social, atuando principalmente nos seguintes temas: psicologia ambiental, comportamento pró-ambeintal, preferência musical, identificação grupal, atitudes, valores humanos e adolescência. 
